\title{
FORMULASI DAN UJI STABILITAS FISIK SEDIAAN MASKER GEL PEEL-OFF EKSTRAK ETANOL DAUN MIANA (Coleus Scutelleroides (L.) Benth.) DENGAN BERBAGAI BASIS
}

\author{
Indriyani Arman ${ }^{1 *}$, Hosea Jaya Edy ${ }^{1)}$, Karlah L.R Mansauda ${ }^{1)}$ \\ ${ }^{1)}$ Program Studi Farmasi FMIPA UNSRAT Manado, 95115 \\ Email: indriyaniarmann@gmail.com
}

\begin{abstract}
Miana leaves (Coleus Scutelleroides (L.) Benth.) contained flavonoid compounds that has antioxidants properties. This study aimed to formulate peel-off gel mask ethanol extract from Miana leaves became peeloff gel mask that is physically stable and to knows the type of base that form a formulation with good physical quality based on the test parameters of physical properties and the stability of preparation. Formulation of peel-off gel mask ethanol extract of miana leaves used three different types of base, they are HPMC, Carbopol, and Na.CMC. Each formula is differentiated based on base of concentration which were HPMC 4\%, carbopol 1\%, and Na.CMC 3\%. Evaluation to predict the physical stability of the preparation included organoleptic test, homogeneity test, $\mathrm{pH}$ test, dispersion test, adhesion test and dry time test. In stability test, each formula is placed at temperature $27{ }^{\circ} \mathrm{C}$ for 28 days and made observation on the 1st, 7 th, 14th, 21th, and 28th day. Based on the result, the ethanol extract of Miana leaves can be formulated into a peel-off mask and formulation with HPMC and Carbopol base has a good physical quality and physically stable compared to Na.CMC base.

Keywords: Miana Leaves, Peel-Off Gel Mask, Stability Teh
\end{abstract}

\begin{abstract}
Abstrak
Daun Miana (Coleus Scutelleroides (L.) Benth.) memiliki kandungan senyawa flavonoid yang berkhasiat sebagai antioksidan. Penelitian ini bertujuan untuk memformulasikan ekstrak etanol daun Miana menjadi masker gel peel-off yang stabil secara fisik serta mengetahui jenis basis yang membentuk formulasi sediaan masker dengan mutu fisik yang baik berdasarkan parameter uji sifat fisik dan stabilitas sediaan. Formulasi sediaan masker gel peel-off ekstrak etanol daun Miana dibuat dengan menggunakan tiga jenis basis yang berbeda yaitu HPMC, karbopol, dan Na.CMC. Masing-masing formula dibedakan berdasarkan basis konsentrasi yaitu HPMC 4\%, karbopol 1\%, dan Na.CMC 3\%. Evaluasi yang dilakukan terhadap stabilitas fisik sediaan masker gel peel-off meliputi uji organoleptis, uji homogenitas, uji $\mathrm{pH}$, uji daya sebar, uji daya lekat, dan uji waktu mengering. Uji stabilitas dilakukan pada suhu kamar $\left(27{ }^{\circ} \mathrm{C}\right)$ selama 28 hari dan dilakukan pengamatan pada hari ke 1, 7, 14, 21, dan 28. Hasil uji stabilitas fisik sediaan masker gel peel-off ekstrak etanol daun Miana dapat diformulasikan dalam bentuk sediaan masker gel peel-off, dan formula masker dengan basis HPMC dan karbopol memiliki mutu fisik yang baik dan stabil secara fisik dibandingkan dengan basis Na.CMC.
\end{abstract}

Kata kunci: Daun Miana, Masker gel peel-off, Uji Stabilitas.

\section{PENDAHULUAN}

Kosmetik yang biasa digunakan untuk kulit wajah memiliki banyak bentuk sediaan. Bahan kosmetik ditujukan untuk kulit wajah seringkali bertujuan untuk regenerasi, mengencangkan, menyegarkan kulit, dan berfungsi sebagai antioksidan. Penggunaan antioksidan pada wajah direkomendasikan dalam bentuk sediaan topikal daripada sediaan oral (Pouillot et al., 2011).

Salah satu kosmetik yang dapat mengatasi kulit kering kusam adalah komposisi masker karena masker mengandung bahan-bahan untuk melembabkan kulit wajah. Penggunaan masker wajah tidak hanya melembabkan kulit, tetapi juga memiliki beberapa manfaat yaitu, melembutkan kulit, membuka pori-pori yang tersumbat oleh kotoran dan residu kosmetik yang tidak dapat dihilangkan oleh pembersih biasa dan mengangkat sel kulit mati (Muliyawan et al., 2013).

Banyak bahan alam yang diketahui dapat digunakan sebagai bahan kosmetik, salah satunya yaitu ekstrak daun miana (Coleus scutelleroides (L.) Benth.) yang memiliki kandungan senyawa flavonoid yang memiliki aktivitas antioksidan 
dapat digunakan untuk perawatan kulit (Podungge, 2017). Pada penelitian yang telah dilakukan sebelumnya, diketahui bahwa ekstrak etanol $96 \%$ daun miana memiliki kandungan flavonoid yang cukup tinggi yaitu rata-rata 8,59 mgRE/gram (Arisanti et al., 2018). Hardiyanti et al. (2013) juga meneliti bahwa ekstrak daun miana mengandung zat antioksidan yaitu antosianin dan memiliki aktivitas antioksidan sebesar $84,64 \%$. Pada penelitian yang telah dilakukan sebelumnya oleh Mardiatul et al. (2016), yang meneliti stabilitas fisik dan aktivitas antioksidan sediaan gel ekstrak etanol daun miana (Coleus scutelleroides (L.) Benth.) diperoleh hasil persen aktivitas antioksidan pada konsentrasi $1 \%$ memiliki aktivitas yang stabil secara fisik. Hasil penelitian tersebut disarankan untuk melakukan pengujian stabilitas ekstrak daun miana dengan menggunakan basis gel yang berbeda, dan saat ini belum ada penelitian ilmiah daun miana (Coleus scutelleroides (L.) Benth.) yang diformulasikan dalam bentuk sediaan masker gel peel-off, dan untuk membuat formulasi masker maka harus memilih bahan dasar yang dapat menggabungkan semua bahan menjadi sediaan yang homogen. Pemilihan jenis basis didasarkan pada sifat-sifat polimer seperti Karbopol, Hidroxy Propil Methyl Cellulose (HPMC), dan Natrium Karboksimetil Selulosa (Na.CMC).

\section{METODOLOGI PENELITIAN Waktu dan Tempat Penelitian}

Penelitian ini dilakukan pada bulan Desember 2020 sampai Maret 2021 di Laboratorium Farmasi Lanjut Divisi Teknologi, Program Studi Farmasi, Fakultas Matematika dan Ilmu Pengetahuan Alam Universitas Sam Ratulangi Manado.

\section{Alat dan Bahan}

a. Alat

Alat-alat yang digunakan pada penelitian adalah peralatan gelas laboratorium (Iwaki Pyrex $\left.{ }^{\circledR}\right)$, hot plate $\left(\mathrm{Nescolab}^{\circledR}\right)$, lemari pendingin $\left(\right.$ Sharp $\left.{ }^{\circledR}\right)$, timbangan analitik (Ae Adam ${ }^{\circledR}$ ), sudip, kaca preparat, alumunium foil, oven, gunting, batang pengaduk, blender, lumpang dan alu, penggaris, corong, stopwatch, kamera, ayakan, pipet mikro, dan $\mathrm{pH}$ meter.

\section{b. Bahan}

Bahan yang digunakan adalah daun miana (Coleus scutelleroides ( $L$ ) Benth.), etanol 96\%, karbopol, Hidroxy Propil Methyl Cellulose

(HPMC), Natrium Karboksimetil Selulosa (Na.CMC), Polivinil Alkohol (PVA), propilenglikol, Trietanolamin (TEA), dan aquadest.

\section{Prosedur Penelitian \\ Ekstraksi}

Ekstrak daun miana dibuat dengan cara maserasi. Serbuk daun miana sebanyak $100 \mathrm{~g}$ yang telah dihaluskan dimasukan kedalam wadah maserasi, kemudian direndam dengan pelarut etanol $96 \%$ sebanyak $500 \mathrm{ml}$ lalu diamkan selama 3 hari sambil sesekali diaduk. Setelah itu dilakukan penyaringan menggunakan kertas saring dan menghasilkan filtrat dan residu. Residu yang ada diremaserasi dengan mengggunakan jenis dan jumlah pelarut yang sama lalu diamkan lagi selama 2 hari. Kemudian filtrat 1 dan 2 digabungkan dan selanjutnya dipekatkan dengan menggunakan oven pada suhu $40^{\circ} \mathrm{C}$ untuk mendapatkan ekstrak kental daun miana.

\section{Formulasi}

Sediaan masker gel peel-off dibuat dengan menggunakan 3 basis yang berbeda, yaitu HPMC $4 \%$, Karbopol 1\%, dan Na.CMC 3\%. Formula masker gel peel-off sebagai berikut.

Tabel 1. Formulasi masker gel peel-off ekstrak etanol daun miana

\begin{tabular}{|c|c|c|c|c|}
\hline \multirow[b]{2}{*}{ Bahan } & \multirow[b]{2}{*}{$\underset{n}{\text { Kegunaa }}$} & \multicolumn{3}{|c|}{ Formulasi } \\
\hline & & F1 (\%) & $\mathrm{F} 2(\%)$ & $\mathrm{F} 3(\%)$ \\
\hline $\begin{array}{c}\text { Ekstrak } \\
\text { daun miana }\end{array}$ & Zat aktif & 1 & 1 & 1 \\
\hline HPMC & Basis gel & 4 & - & - \\
\hline Karbopol & Basis gel & - & 1 & - \\
\hline $\mathrm{Na} . \mathrm{CMC}$ & Basis gel & - & - & 3 \\
\hline PVA & $\begin{array}{c}\text { Filming } \\
\text { agent }\end{array}$ & 14 & 14 & 14 \\
\hline TEA & Surfaktan & 1 & 1 & 1 \\
\hline $\begin{array}{l}\text { Propilengli } \\
\text { kol }\end{array}$ & $\begin{array}{c}\text { Humekta } \\
n\end{array}$ & 15 & 15 & 15 \\
\hline $\begin{array}{c}\text { Metil } \\
\text { Paraben }\end{array}$ & Pengawet & 0,2 & 0,2 & 0,2 \\
\hline Aquadest & Pelarut & $\begin{array}{l}\text { Ad } \\
100\end{array}$ & $\begin{array}{c}\mathrm{Ad} \\
10 \\
0\end{array}$ & $\begin{array}{c}\mathrm{Ad} \\
10 \\
0\end{array}$ \\
\hline
\end{tabular}




\section{Pembuatan Sediaan Masker Gel Peel-off}

Sediaan masker gel dibuat dengan cara masing-masing basis dikembangkan terlebih dahulu. Basis Karbopol, HPMC, dan Na.CMC dikembangkan dalam aquadest dan didiamkan hingga mengembang selama 1x24 jam. Karbopol dan Na.CMC dikembangkan menggunakan aquadest $70^{\circ} \mathrm{C}$ hingga mengembang membentuk basis, sedangkan HPMC dikembangkan menggunakan aquadest dingin $29^{\circ} \mathrm{C}$ dan diaduk terus menerus hingga mengembang. PVA dilarutkan dengan aquadest $80^{\circ} \mathrm{C}$ lalu dipanaskan diatas penangas dan diaduk hingga homogen, dimasukkan masing-masing basis gel dan TEA kedalam massa PVA dan diaduk sampai homogen. Metil paraben dilarutkan dalam propilenglikol lalu dimasukkan ke dalam basis, setelah itu dimasukkan ekstrak daun miana yang telah diencerkan dengan aquadest secara bertahap sambil diaduk hingga homogen.

\section{Evaluasi Sediaaan}

\section{a. Uji Organoleptik}

Uji organoleptik dilakukan dengan cara mengamati secara langsung perubahan yang terjadi pada sediaan masker gel, seperti perubahan warna, bau, dan bentuk (Septiani et al., 2011).

b. Uji Homogenitas

Sediaan masker gel sebanyak 1 g dioleskan pada kaca preparat, diamati apakah ada bagian yang tidak tercampur. Sediaan masker gel harus memiliki susunan yang homogen dan tidak adanya butir-butir kasar terlihat (Septiani et al., 2011).

\section{c. $\mathrm{Uji} \mathrm{pH}$}

Uji $\mathrm{pH}$ menggunakan $\mathrm{pH}$ meter dengan cara sediaan masker ditimbang $1 \mathrm{~g}$ kemudian dilarutkan dalam $10 \mathrm{ml}$ aquadest dan diaduk hingga merata, setelah itu dicelupkan $\mathrm{pH}$ meter kedalam larutan dan dicatat hasilnya. Sediaan masker gel yang dibuat harus memiliki $\mathrm{pH}$ yang sesuai dengan $\mathrm{pH}$ kulit, yaitu 4,5-6,5 (Tranggono et al., 2007)

d. Uji Daya Sebar

Sediaan masker gel sebanyak 1 g dioleskan pada kaca, kemudian dioleskan pada kaca lain diatas sediaan dan diberikan pemberat $150 \mathrm{~g}$ selama 1 menit, lalu diukur diameternya. Sediaan masker gel yang baik memiliki daya sebar antara 5-7 cm (Shovyana et al., 2013).

e. Uji Daya Lekat
Sediaan masker gel sebanyak $1 \mathrm{~g}$ dioleskan pada kaca preparat yang ditutup dengan kaca preparat lain, kemudian diberikan pemberat $250 \mathrm{~g}$ selama 5 menit. Kaca preparat dipasangkan pada alat uji dan dilakukan pengukuran waktu daya lekat yang dimulai saat pemberat pada alat uji dilepas hingga lepasnya kedua kaca preparat. Sediaan masker gel sebaiknya memiliki daya lekat lebih dari 4 detik (Septiani et al., 2011).

f. Uji Waktu Mengering

Sediaan masker gel sebanyak $1 \mathrm{~g}$ dioleskan pada punggung tangan, kemudian dihitung waktu mengering sediaan masker sampai mengering membentuk lapisan film menggunakan stopwatch. Waktu kering sediaan masker gel yang baik yaitu antara 15-30 menit (Vieira, 2009).

\section{g. Uji Stabilitas}

Sediaan masker gel diuji stabilitasnya dengan memperhatikan perubahan warna, bentuk, bau, homogenitas, $\mathrm{pH}$, daya sebar, daya lekat, dan waktu mengering. Formulasi sediaan sebanyak $100 \mathrm{~g}$ masing-masing ditempatkan dalam suhu kamar $\left(27^{\circ} \mathrm{C}\right)$ selama 28 hari, serta dilakukan pengamatan pada hari ke 1, 7, 14, 21, dan 28 (Priani et al., 2015).

\section{HASIL DAN PEMBAHASAN Ekstraksi}

Sampel daun Miana diperoleh sebanyak 2 $\mathrm{kg}$ dan sampel kering memiliki berat hingga 1,1 $\mathrm{kg}$. Pengeringan bertujuan untuk mengurangi kadar air daun Miana. Salah satu tanda sampel kering adalah menjadi rapuh saat diremas dengan tangan. Kerapuhan sampel ini menunjukkan bahwa sampel tersebut mengandung kurang dari $10 \%$ air (Sitepu, 2010) dan pengeringan mencegah pertumbuhan jamur sehingga sampel dapat disimpan untuk jangka waktu yang lama. Hasil serbuk simplisia yang diperoleh sebanyak 100 g. Pada penelitian ini, ekstraksi yang dilakukan menggunakan metode maserasi. Proses maserasi memiliki keunggulan lain dibandingkan metode ekstraksi lainnya, yaitu cara pengerjaannya sederhana, peralatannya mudah ditemukan dan tidak memerlukan alat khusus. Pelarut yang digunakan dalam ekstraksi ini adalah etanol 96\%. Menurut Runadi (2007), etanol merupakan pelarut universal yang dapat menarik sebagian besar senyawa yang ada dalam tumbuhan, dan selektif dalam melarutkan 
senyawa yang dinginkan serta lebih efisien dalam degradasi dinding sel sehingga senyawa seperti flavonoid akan tersari lebih banyak. Berat ekstrak kental yang diperoleh selama proses maserasi adalah $8,7 \mathrm{~g}$.

\section{Evaluasi Sediaan Masker Gel peel-off}

a. Uji Organoleptik

Uji organoleptik dilakukan dengan melihat secara visual dan mengamati perubahan warna, bau, dan bentuk dari formulasi masker gel selama penyimpanan pada suhu kamar selama 28 hari. Hasil pengamatan organoleptik ditunjukkan pada Tabel 2.

Tabel 2. Hasil Uji Organoleptik Sediaan pada Suhu Kamar $\left(27^{\circ} \mathrm{C}\right)$

\begin{tabular}{|c|c|c|c|c|}
\hline \multirow{2}{*}{ Formula } & \multirow{2}{*}{ Kondisi } & \multicolumn{3}{|c|}{ Jenis Pemeriksaan } \\
\hline & & Warna & Bau & Bentuk \\
\hline \multirow{11}{*}{$\begin{array}{c}\text { F1 } \\
\text { (basis } \\
\text { HPMC) }\end{array}$} & Sebelum & Coklat & Khas & Semi \\
\hline & Penyimpanan & Gelap & Ekstrak & Solid \\
\hline & $\begin{array}{c}\text { Sesudah } \\
\text { Penyimpanan }\end{array}$ & & & \\
\hline & Hari ke-7 & Coklat & Khas & Semi \\
\hline & & Gelap & Ekstrak & Solid \\
\hline & Hari ke-14 & Coklat & Khas & Semi \\
\hline & & Gelap & Ekstrak & Solid \\
\hline & Hari ke-21 & Coklat & Khas & Semi \\
\hline & & Gelap & Ekstrak & Solid \\
\hline & Hari ke-28 & Coklat & Khas & Semi \\
\hline & & Gelap & Ekstrak & Solid \\
\hline \multirow{11}{*}{$\begin{array}{c}\mathrm{F} 2 \\
\text { (basis } \\
\text { karbopol } \\
\text { ) }\end{array}$} & Sebelum & Coklat & Khas & Semi \\
\hline & Penyimpanan & Gelap & Ekstrak & Solid \\
\hline & Sesudah & & & \\
\hline & Penyimpanan & & & \\
\hline & Hari ke-7 & $\begin{array}{l}\text { Coklat } \\
\text { Gelap }\end{array}$ & $\begin{array}{c}\text { Khas } \\
\text { Ekstrak }\end{array}$ & $\begin{array}{l}\text { Semi } \\
\text { Solid }\end{array}$ \\
\hline & Hari ke- & Coklat & Khas & Semi \\
\hline & 14 & Gelap & Ekstrak & Solid \\
\hline & Hari ke- & Coklat & Khas & Semi \\
\hline & 21 & Gelap & Ekstrak & Solid \\
\hline & Hari ke- & Coklat & Khas & Semi \\
\hline & 28 & Gelap & Ekstrak & Solid \\
\hline \multirow{12}{*}{$\begin{array}{c}\text { F3 } \\
\text { (basis } \\
\text { Na.CMC) }\end{array}$} & Sebelum & Coklat & Khas & Semi \\
\hline & $\begin{array}{c}\text { Penyimpa } \\
\text { nan }\end{array}$ & Gelap & Ekstrak & Solid \\
\hline & Sesudah & & & \\
\hline & $\begin{array}{l}\text { Penyimpa } \\
\text { nan }\end{array}$ & & & \\
\hline & Hari ke-7 & Coklat & Khas & Semi \\
\hline & & Gelap & Ekstrak & Solid \\
\hline & Hari ke- & Coklat & Khas & Semi \\
\hline & 14 & Gelap & Ekstrak & Solid \\
\hline & Hari ke- & Coklat & Khas & Semi \\
\hline & 21 & Gelap & Ekstrak & Solid \\
\hline & Hari ke- & Coklat & Khas & Semi \\
\hline & 28 & Gelap & Ekstrak & Solid \\
\hline
\end{tabular}

Pengamatan organoleptik menunjukkan bahwa masker gel peel-off esktrak etanol daun
Miana yang dibuat dengan menggunakan 3 basis yang berbeda tidak mengalami adanya perubahan 
warna, bau, dan bentuk baik itu sebelum maupun setelah penyimpanan selama 28 hari pada suhu kamar. Bau dan warna sediaan berasal dari ekstrak daun Miana. Warna coklat pada masker disebabkan oleh proses degradasi pigmen klorofil pada daun Miana. Perubahan warna daun menjadi kecoklatan juga berkaitan dengan kadar air daun yang melibatkan reaksi enzimatis. Semakin lama proses pengeringan, semakin lama air berada di dalam simplisia maka semakin besar memungkinkan terjadinya reaksi degragasi klorofil menjadi feofitin yang berwarna coklat. Hasil studi secara visual menunjukkan bahwa waktu curing (pengeringan) yang lebih lama, menurunkan intensitas warna daun dan meningkatkan intensitas warna coklat bertambah (Wiraguma et al., 2010).

b. Uji Homogenitas

Uji homogenitas bertujuan untuk mengetahui homogenitas suatu sediaan dan mengidentifikasi kemungkinan terjadinya perubahan. Sediaan homogen ditunjukkan dengan tidak adanya partikel atau butiran kasar dalam sediaan. Hasil uji homogenitas ditunjukkan pada tabel 3.

Tabel 3. Hasil Uji Homogenitas Sediaan pada Suhu Kamar $\left(27^{\circ} \mathrm{C}\right)$

\begin{tabular}{|c|c|c|c|c|c|}
\hline \multirow{3}{*}{ Formula } & \multicolumn{5}{|c|}{ Homogenitas } \\
\hline & \multirow{2}{*}{$\begin{array}{c}\text { Sebelum } \\
\text { Penyimpana } \\
\mathbf{n}\end{array}$} & \multicolumn{4}{|c|}{ Sesudah Penyimpanan } \\
\hline & & 7 & 14 & 21 & 28 \\
\hline $\begin{array}{c}\text { F1 } \\
\text { (basis } \\
\text { HPMC) }\end{array}$ & Homogen & $\begin{array}{c}\text { Homoge } \\
n\end{array}$ & $\begin{array}{c}\text { Homoge } \\
n\end{array}$ & $\begin{array}{c}\text { Homoge } \\
n\end{array}$ & $\begin{array}{c}\text { Homoge } \\
\mathrm{n}\end{array}$ \\
\hline $\begin{array}{c}\text { F2 } \\
\text { (basis } \\
\text { karbopol) }\end{array}$ & Homogen & $\begin{array}{c}\text { Homoge } \\
n\end{array}$ & $\begin{array}{c}\text { Homoge } \\
n\end{array}$ & $\begin{array}{c}\text { Homoge } \\
n\end{array}$ & $\begin{array}{c}\text { Homoge } \\
\mathrm{n}\end{array}$ \\
\hline $\begin{array}{c}\text { F3 } \\
\text { (basis } \\
\text { Na.CMC) }\end{array}$ & Homogen & $\begin{array}{c}\text { Homoge } \\
n\end{array}$ & $\begin{array}{c}\text { Homoge } \\
n\end{array}$ & $\begin{array}{c}\text { Homoge } \\
n\end{array}$ & $\begin{array}{c}\text { Homoge } \\
\mathrm{n}\end{array}$ \\
\hline
\end{tabular}

Hasil uji dari ketiga formula menunjukkan bahwa F1 (basis HPMC), F2 (basis Karbopol) dan F3 (basis Na.CMC) homogen dan tidak mengalami perubahan baik sebelum maupun sesudah penyimpanan pada suhu kamar selama 28 hari. Hasil pengamatan menunjukkan homogenitas yang baik karena semua sediaan bebas partikel kasar saat masker gel dioleskan pada kaca preparat. Formula yang dibuat dapat dikatakan stabil karena memiliki komposisi yang homogen dan hal ini menunjukkan bahwa bahan- bahan yang terkandung di dalamnya sudah cukup tercampur dengan baik (Fitriana, 2012).

c. $\mathrm{Uji} \mathrm{pH}$

Uji $\mathrm{pH}$ bertujuan untuk menentukan $\mathrm{pH}$ formula yang sesuai dengan $\mathrm{pH}$ kulit agar meminimalkan reaksi iritasi pada saat pemakaian. Masker gel peel-off adalah sediaan yang digunakan untuk kulit wajah dan nilai $\mathrm{pH}$ dari sediaan tersebut harus sesuai dengan $\mathrm{pH}$ kulit wajah yaitu 4,5-6,5. Hasil uji $\mathrm{pH}$ ditunjukkan pada

Tabel 4. Hasil Uji pH Sediaan pada Suhu Kamar $\left(27^{\circ} \mathrm{C}\right)$

\begin{tabular}{cccccc}
\hline & \multicolumn{5}{c}{ Rata-Rata Nilai pH } \\
\cline { 2 - 6 } Formula & $\begin{array}{c}\text { Sebelum } \\
\text { Penyimpana }\end{array}$ & \multicolumn{5}{c}{ Sesudah Penyimpanan } \\
\cline { 3 - 6 } & $\mathbf{n}$ & $\mathbf{7}$ & $\mathbf{1 4}$ & $\mathbf{2 1}$ & $\mathbf{2 8}$ \\
\hline $\begin{array}{c}\text { F1 } \\
\text { (basis } \\
\text { HPMC) }\end{array}$ & 6,39 & 6,16 & 5,88 & 6,14 & 6,05 \\
\hline F2 & 6,31 & 6,13 & 6,23 & 6,01 & 6,13 \\
\hline
\end{tabular}




\begin{tabular}{cccccc}
\hline $\begin{array}{c}\text { (basis } \\
\text { karbopol) }\end{array}$ & & & & & \\
\hline $\begin{array}{c}\text { F3 } \\
\text { (basis }\end{array}$ & 5,93 & 5,79 & 6,02 & 5,87 & 5,70 \\
Na.CMC) & & & & & \\
\hline
\end{tabular}

Hasil pengujian $\mathrm{pH}$ yang diperoleh menunjukkan bahwa nilai pH F1 (basis HPMC), F2 (basis Karbopol) dan F3 (basis Na.CMC) memenuhi syarat rentang $\mathrm{pH}$ yang dapat diterima oleh kulit. Nilai $\mathrm{pH}$ suatu sediaan jika terlalu asam $<$ 4,5 dapat menyebabkan kulit iritasi, sedangkan jika terlalu basa > 6,5 dapat menyebabkan kulit bersisik (Rahmawanty et al., 2015). Nilai pH pada sediaan terjadi penurunan tetapi tetap dalam rentang $\mathrm{pH}$ normal, karena disebabkan kandungan senyawa flavonoid yang sedikit asam yang terkandung dalam ekstrak daun Miana (Podungge et al., 2017). Menurut Young et al. (2002) perubahan $\mathrm{pH}$ dalam formulasi kemungkinan akan dipengaruhi oleh lingkungan yang terdekomposisi pada suhu tinggi selama pembuatan atau penyimpanan yang menghasilkan asam atau basa, dan penyimpanan yang kurang baik.

d. Uji Daya Sebar

Uji daya sebar digunakan untuk menentukan kemampuan menyebar sediaan masker gel ketika diaplikasikan pada kulit, semakin besar permukaan kontak sediaan, maka semakin baik penyerapan zat ke dalam kulit. Hasil uji daya sebar ditunjukkan pada Tabel 5.

Tabel 5. Hasil Uji Daya Sebar Sediaan pada Suhu Kamar $\left(27^{\circ} \mathrm{C}\right)$

\begin{tabular}{cccccc}
\hline \multirow{2}{*}{ Formula } & \multicolumn{5}{c}{ Rata-Rata Diameter Daya Sebar $(\mathbf{c m})$} \\
\cline { 2 - 6 } & $\begin{array}{c}\text { Sebelum } \\
\text { Penyimpanan }\end{array}$ & \multicolumn{5}{c}{ Sesudah Penyimpanan } \\
\cline { 3 - 6 } F1 & $\mathbf{7}$ & $\mathbf{1 4}$ & $\mathbf{2 1}$ & $\mathbf{2 8}$ \\
\hline $\begin{array}{c}\text { (basis } \\
\text { HPMC) }\end{array}$ & 5,9 & 6,5 & 5,7 & 5,2 & 5,1 \\
\hline $\begin{array}{c}\text { F2 } \\
\text { (basis }\end{array}$ & 5,4 & 5,6 & 5,7 & 5,9 & 6,0 \\
karbopol) & & & & & \\
\hline $\begin{array}{c}\text { F3 } \\
\text { (basis } \\
\text { Na.CMC) }\end{array}$ & 5,1 & 4,7 & 4,6 & 4,4 & 4,2 \\
\hline
\end{tabular}

Hasil pengujian daya sebar yang diperoleh menunjukkan bahwa ketiga formula sediaan masker gel peel-off sebelum penyimpanan menunjukkan daya sebar yang baik. Hasil uji daya sebar setelah penyimpanan selama 28 hari untuk F1 (basis HPMC) dan F2 (basis karbopol) berada pada standar daya sebar yang baik, sedangkan untuk F3 (basis Na.CMC) menunjukkan daya sebar yang kurang baik $<5 \mathrm{~cm}$. Hal ini dikarenakan F3 (basis Na.CMC) adalah formula dengan konsistensi paling kental yang dimana semakin kental sediaan, maka semakin kecil kemungkinannya akan menyebar. Penurunan daya sebar selama penyimpanan dapat terjadi karena tertahannya cairan pelarut yang diabsorbsi oleh agen pembentuk gel (gelling agent). Gelling agent
Na-CMC mempunyai daya kohesi yang besar yang dapat menyebabkan interaksi diantara molekul sejenis menjadi lebih besar sehingga penyebaran sediaan menjadi sulit (Maulina et al., 2015).

e. Uji Daya Lekat

Uji daya lekat bertujuan untuk mengukur lamanya waktu kontak sediaan dengan permukaan kulit, suatu sediaan dapat dikatakan baik apabila mempunyai daya lekat yang besar. Kemampuan melekat suatu sediaan yang rendah akan mengakibatkan sediaan mudah lepas dari kulit dan efek yang diberikan tidak maksimal. Daya melekat sediaan yang baik adalah lebih dari 4 detik (Septiani et al., 2011). Hasil uji daya lekat ditunjukkan pada Tabel 6. 
Tabel 6. Hasil Uji Daya Lekat Sediaan pada Suhu Kamar $\left(27^{\circ} \mathrm{C}\right)$

\begin{tabular}{|c|c|c|c|c|c|}
\hline \multirow{3}{*}{ Formula } & \multicolumn{5}{|c|}{ Rata-Rata Daya Lekat (detik) } \\
\hline & \multirow{2}{*}{$\begin{array}{c}\text { Sebelum } \\
\text { Penyimpana } \\
\text { n }\end{array}$} & \multicolumn{4}{|c|}{ Sesudah Penyimpanan } \\
\hline & & 7 & 14 & 21 & 28 \\
\hline $\begin{array}{c}\text { F1 } \\
\text { (basis } \\
\text { HPMC) }\end{array}$ & 24,75 & $\begin{array}{c}25,3 \\
2\end{array}$ & $\begin{array}{c}26,0 \\
4\end{array}$ & $\begin{array}{c}26,4 \\
7\end{array}$ & 26,98 \\
\hline $\begin{array}{c}\mathrm{F} 2 \\
\text { (basis } \\
\text { karbopol) }\end{array}$ & 20,07 & $\begin{array}{c}19,5 \\
8\end{array}$ & $\begin{array}{c}19,0 \\
9\end{array}$ & $\begin{array}{c}18,5 \\
1\end{array}$ & 17,44 \\
\hline $\begin{array}{c}\text { F3 } \\
\text { (basis } \\
\text { Na.CMC) }\end{array}$ & 29,12 & $\begin{array}{c}29,5 \\
2\end{array}$ & $\begin{array}{c}30,0 \\
6\end{array}$ & $\begin{array}{c}30,5 \\
9\end{array}$ & 31,12 \\
\hline
\end{tabular}

Hasil pengujian daya lekat yang diperoleh setelah penyimpanan selama 28 hari pada suhu kamar menunjukkan bahwa ketiga formula sediaan masker gel peel-off yaitu F1 (basis HPMC), F2 (basis Karbopol) dan F3 (basis Na.CMC) memenuhi persyaratan secara teoritis. Formula memiliki daya lekat masing-masing yang cenderung semakin menurun, menurut Rahmawanty et al. (2015), daya lekat sediaan masker gel yang menurun akibat oksidasi komponen masker gel sehingga terjadi penurunan daya lekat, namun daya lekat ketiga formula masih memenuhi syarat. f. Uji Waktu Mengering

Salah satu syarat yang harus dipenuhi oleh sediaan masker gel peel-off adalah kemampuan formula untuk mengering saat diaplikasikan pada kulit. Uji waktu mengering bertujuan untuk mengetahui waktu yang dibutuhkan sediaan untuk mengering dan membentuk lapisan film. Waktu mengering sediaan masker gel peel-off yang baik adalah 1530 menit (Vieira, 2009). Hasil uji waktu mengering ditunjukkan pada Tabel 7.

Tabel 7. Hasil Uji Waktu Mengering Sediaan pada Suhu Kamar $\left(27^{\circ} \mathrm{C}\right)$

\begin{tabular}{|c|c|c|c|c|c|}
\hline \multirow{3}{*}{ Formula } & \multicolumn{5}{|c|}{ Rata-Rata Waktu Mengering (menit/detik) } \\
\hline & \multirow{2}{*}{$\begin{array}{c}\text { Sebelum } \\
\text { Penyimpa } \\
\text { nan }\end{array}$} & \multicolumn{4}{|c|}{ Sesudah Penyimpanan } \\
\hline & & 7 & 14 & 21 & 28 \\
\hline $\begin{array}{c}\text { F1 } \\
\text { (basis } \\
\text { HPMC) }\end{array}$ & 23,76 & 24,62 & 25,32 & $\begin{array}{c}26,0 \\
3\end{array}$ & 26,86 \\
\hline $\begin{array}{c}\mathrm{F} 2 \\
\text { (basis } \\
\text { karbopol) }\end{array}$ & 15,56 & 16,62 & 18,06 & $\begin{array}{c}19,8 \\
4\end{array}$ & 21,87 \\
\hline $\begin{array}{c}\text { F3 } \\
\text { (basis } \\
\text { Na.CMC) }\end{array}$ & 29,97 & 31,67 & 33,54 & $\begin{array}{c}34,8 \\
3\end{array}$ & 36,45 \\
\hline
\end{tabular}


Hasil pengujian waktu mengering sediaan yang diperoleh setelah penyimpanan selama 28 hari pada suhu kamar menunjukkan bahwa formula F1 (basis HPMC) dan F2 (basis Karbopol) masih pada rentang waktu sesuai persyaratan, sedangkan untuk F3 (basis Na.CMC) memiliki waktu sediaan mengering lebih lama setelah penyimpanan dan sudah tidak memenuhi syarat sediaan. Hasil yang diperoleh menunjukkan bahwa semakin lama penyimpanan, maka semakin lama formula masker gel mengering karena waktu yang dibutuhkan sediaan untuk mengering semakin meningkat. Hal ini dapat disebabkan karena banyaknya kandungan air pada formula dapat memperlambat penguapan dan memperpanjang waktu mengering sediaan (Shovyana et al., 2013). Formula masker gel peeloff juga mengandung propilenglikol sebagai humektan sehingga kenaikan waktu kering juga dapat dipengaruhi oleh propilenglikol yang bersifat higroskopis dengan afinitas yang tinggi untuk menarik dan menahan molekul air dengan cara mengabsorbsi lembab dari lingkungan dan mengurangi penguapan air dari formula (Shovyana et al., 2013).

\section{KESIMPULAN}

1. Ekstrak etanol daun Miana (Coleus scutelleroides (L.) Benth.) dapat diformulasikan dalam bentuk sediaan masker gel peel-off yang stabil secara fisik.

2. Formula masker gel peel-off ekstrak etanol daun Miana (Coleus scutelleroides (L.) Benth.) dengan basis HPMC dan karbopol memiliki mutu fisik yang baik dan stabil dibandingkan dengan basis Na.CMC.

\section{DAFTAR PUSTAKA}

Arisanti, D., dan A. Fatmawati. 2018. Potensi Flavonoid Ekstrak Daun Miana (Coleus atropurpereus) Sebagai Senyawa Anti Mycobacterium tuberculosis Strain H37rv Dan Mdr Dengan Microscopy Observation Drug Susceptibility (Mods). Jurnal Ilmu Alam dan Lingkungan. 9(18): 61-73.

Fitriana, N. 2012. Formulasi Gel Ekstrak Daun Beluntas (Pluceaindica Less) dengan NaCMC sebagai Basis Gel. Journal of Pharmaceutical Science and Herbal Technology. 1(1): 41-44.

Hardiyanti,Y., Djaswir D., dan A. Santoni. 2013. Ekstraksi dan Uji Antioksidan Senyawa Antosianin dari Daun Miana (Coleus scutellarioides L.(Benth)) serta Aplikasi Pada Minuman. Jurnal Kimia Unand. 2(2): 44-50.

Mardiatul, U., Aditya, F., dan A.M. Masrumin. 2016. Stabilitas Fisik Dan Aktivitas Antioksidan Sediaan Gel Berbahan Aktif Ekstrak Etanol Daun Miana (Coleus Antropurpureus Bent.). Jurnal Proceeding of Mulawarman Pharmaceuticals Conferences. 3(2): 8795.

Maulina, L., dan N. Sugihartini. 2015. Formulasi Gel Ekstrak Etanol Kulit Buah Manggis (Garcinia mangostana L.) dengan Variasi Gelling Agent Sebagai Sediaan Luka Bakar. Jurnal Pharmaciana. 5(1): 43-52.

Muliyawan, D., dan N. Suriana. 2013. A-Z tentang Kosmetik. PT Elex Media Komputindo, Jakarta.

Rahmawanty, D., N. Yulianti, dan M. Fitriana. 2015. Formulasi dan Evaluasi Masker Wajah Peel-off Mengandung Kuersetin Dengan Variasi Konsentrasi Gelatin dan Gliserin. Media Farmasi. 12(1): 17-32.

Septiani, S.N., Wathoni dan S.R. Mita. 2011. Formulasi Sediaan Masker Antioksidan dari Ekstrak Etanol Biji Melinjo (Gnetum Gnemon L.). Jurnal Unpad. 1: 4-24.

Shovyana, H.H., dan A.K. Zulkarnain. 2013. Stabilitas Fisik Dan Aktivitas Krim W/O Ekstrak Etanolik Buah Mahkota Dewa (Phaleria macrocarph(scheff.) Boerl) Sebagai Tabir Surya. Traditional Medicine Journal. 18(2):109-117.

Tranggono, R.I., dan F. Latifah. 2007. Buku Pegangan Ilmu Pengetahuan Kosmetik. PT. Gramedia Pustaka Utama, Jakarta.

Vieira, P.R., Fernandes, R.A., Kaneko, M.T., and R.V. Velasco. 2009. Physicaland Physicochemical Stability Evaluation of Cosmetic Formulations Containing Soybean Extract Fermented by Bifidobacterium animalis. Brazilian Journal of Pharmaceutical Sciences. 45(3): 515-525.

Young, B.A. 2002. Practical Cosmetic Science. Mills and Boon, London. 